\title{
A leitura do café: suas possíveis relações matemáticas e a perspectiva de genêro
}

\section{The reading of coffee: its possible mathematical relations and the prospect of gender}

\author{
Ms. Glauce Maris Pereira Barth*
}

\begin{abstract}
RESUMO
Este artigo revela a interdisciplinaridade entre Arte, Matemática e História, revelando o quanto elas são justapostas. Foi abordada a leitura de imagem envolvendo a ótica de gênero na obra "Café" do artista Cândido Portinari. Há uma abordagem da história do café e uma discussão das possíveis relações matemáticas que a obra oferece. Houve uma preocupação em aliar a leitura tanto histórica quanto da linguagem do pensamento e percepção visual.

Palavras-chave: leitura de imagem; arte, matemática; história do café; percepção visual.
\end{abstract}

\begin{abstract}
This article reveals the interdisciplinary between art, mathematics and history, showing how they are juxtaposed. It was addressed to read the image involving a gender perspective in the painting "Coffee" of the artist Candido Portinari. One approach the history of coffee and a discussion of possible mathematical relationships that the work offers. There was a concern to combine both historic and the reading of the language of thought and visual perception.

Keywords: reading the image; art; mathematics; history of coffee; visual perception.

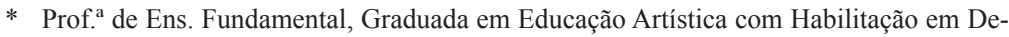
senho, Mestra em Educação pela UFPR. Contato pelo e-mail: glaucebarth@pop.com.br
\end{abstract}




\section{A lenda do café ${ }^{1}$}

Era uma vez, há mais de mil anos, um monge que passava pelas pastagens da Arábia quando, de repente, notou uma grande agitação onde umas cabras pastavam. Impressionado com a alegria dos animais, o monge resolveu verificar mais de perto o que acontecia. Junto às cabras, estava um jovem pastor, chamado Kaldi, que cantarolava. O quadro era de total êxtase. $\mathrm{O}$ monge, muito curioso, notou que nas mãos do pastor havia uma pequena frutinha de cor vermelha. $O$ pastor contou então que aquela frutinha era a responsável por toda aquela felicidade e motivação. Apenas com a ajuda dela o rebanho conseguia caminhar por muitos quilômetros com muita disposição. $\mathrm{O}$ monge não teve dúvidas, apanhou um punhado da fruta e levou para o seu monastério. Um pouco antes da oração noturna, ele resolveu experimentar. Sentiu então seu corpo tomado por uma agradável sensação de júbilo e motivação. O monge orou a noite inteira e agradeceu ao novo elixir a súbita disposição. Surgia, então, a nova bebida, considerada a fórmula ideal para deixar os monges acordados durante as rezas e os longos períodos de meditação.

\section{Um pouco de História}

Acredita-se que a planta café é originária da Etiópia, área central da África. Esse dado não possui comprovação histórica, porém foi a Arábia a principal propagadora da cultura do café, utilizava o nome gahwa, cujo significado é vinho. Assim, no século XIV, ao chegar à Europa, o café passou a ser conhecido como "vinho da Arábia".

O café era gostoso mesmo e a sementinha vermelha vinha com outros atrativos: era exótica como as drogas do Oriente, como se fosse uma especiaria, o que acabava por torná-la uma bebida rara, encontrada em

1 Lenda retirada na íntegra do site $<\mathrm{http}: / /$ www.cafesdobrasil.com.br/expresso/historia. $\mathrm{htm}>$. Acesso em: 10/02/2008. 
poucas mesas, chique, cobiçada e, finalmente, muito apreciada. Era o "licor do Oriente". Em breve seria o "licor dos trópicos" (MARTINS, 1990, p. 4).

Os árabes tinham o monopólio sobre o cultivo da planta e da preparação da bebida, a qual não tinha as características do café que conhecemos hoje, a semente do café era fervida e degustada como se fosse um chá. Os árabes cuidavam para que estrangeiros não se aproximassem da plantação e, também, não tivessem acesso à produção da bebida.

Em 1475, foi criada uma lei na qual à mulher era permitido o divórcio, caso o marido fosse incapaz de lhe proporcionar uma quantidade diária da bebida (PASCOAL, 1999).

Comerciantes holandeses levaram para a Europa o café, somente assim os europeus puderam saborear a bebida.

"Apesar das excelentes qualidades atribuídas à fruta exótica do Oriente, não foi fácil a aceitação do café nos centros civilizados europeus no século XVI" (MARTINS, 1990, p. 3). O café foi uma bebida estranha e estrangeira que invadiu a Europa, onde o chá, principalmente de erva, era a principal bebida.

Em meados do século XVI, na Pérsia, os primeiros grãos de café passaram a ser torrados e então, transformados na bebida café.

Os holandeses foram os primeiros a acabar com o monopólio do café pelos árabes, embora, alemães, italianos e franceses tivessem tentado cultivar a planta, sem sucesso. Foram nas estufas do jardim botânico de Amsterdã que as primeiras mudas conseguiram ser cultivadas e, logo, o café passou a fazer parte do consumo europeu, sendo levado por eles também para a América do Norte.

Muitas outras experiências foram iniciadas pelos holandeses em relação ao cultivo da planta. Mas essa, em particular, trouxe sucesso e muito lucro ao país, encorajando outros a partirem para a aventura desse cultivo. O café tornou-se, também, inspirativo e encorajou artistas como o músico e compositor alemão Johann Sebastian Bach (1685-1750): "Na Alemanha, a moda do café foi tamanha que o compositor, Johann Sebastian Bach, compôs, em 1732, a 'A Cantata do café', em que exaltava as qualidades do café” (MARTINS, 1990, p. 4).

Como o consumo do café foi muito grande, propiciou a expansão para outros países, chegando ao Centro e Sul da América, através da Guiana Francesa, o Brasil teve acesso ao cultivo da planta. Desta maneira, o segredo que os árabes tanto prezaram se espalhou pelo mundo todo.

O sargento-mor Francisco de Mello Palheta enviado à Guiana Francesa, a pedido do governador do Maranhão e Grão-Pará, em 1727, teve a missão de trazer o café para o Brasil, pois possuía grande valor comercial. Clandestina- 
mente, conseguiu trazer em meio a sua bagagem uma muda da planta.

Como o clima brasileiro foi favorável ao cultivo do café, a produção se espalhou rapidamente, passando do Pará para outros estados brasileiros como: Maranhão, Bahia, Rio de Janeiro, São Paulo, Paraná e Minas Gerais, trazendo para o país crescimento econômico. O café passou a ser a principal riqueza do comércio interno.

A produção cafeeira necessitou, então, de uma grande mão de obra. Os fazendeiros utilizaram, inicialmente, escravos e escravas nas lavouras e, depois, substituiu-os por colonos, exigindo dos trabalhadores, grande cuidado com a planta durante a colheita do fruto.

Homens e mulheres livres ou não, com seus trabalhos manuais colaboraram para o desenvolvimento da economia cafeeira brasileira e por quase um século, o café foi a principal riqueza cultivada, acelerando o desenvolvimento do Brasil. As primeiras exportações aconteceram no ano de 1779, iniciando com a quantia de 79 arrobas $^{2}$.

O Brasil passou por muitas crises. Entre elas, a crise da mão de obra, neste caso, a escrava que foi muito significativa. "Após 1850, ano da lei da abolição do tráfico, os preços praticamente triplicaram. Em 1865, uma escrava valia mais do que o escravo homem, pois seu papel reprodutor tornava-a mais valiosa" (MARTINS, 1990, p. 69). Confira os preços na tabela abaixo:

\begin{tabular}{|c|c|c|c|}
\hline \multicolumn{4}{|c|}{ PREÇOS MÉDIOS (em mil-réis) } \\
\hline Ano & Homens & Mulheres & Média \\
\hline 1835 & 375 & 359 & 367 \\
\hline 1845 & 384 & 371 & 378 \\
\hline 1855 & 1075 & 857 & 966 \\
\hline 1865 & 972 & 1145 & 1059 \\
\hline 1875 & 1256 & 1106 & 1181 \\
\hline
\end{tabular}

FONTE: Martins (apud BUESU, História econômica do Brasil, p. 245).

Em 1870, o Brasil passou por uma crise na cafeicultura, mas superou-a e, ainda hoje, em regiões dos Estados de Rondônia, Bahia, Minas Gerais, Espírito Santo, de São Paulo e Paraná, o café continua a ser um dos produtos mais importantes para o Brasil e é, sem dúvida, o mais brasileiro de todos. Hoje, o país é o primeiro produtor e o segundo consumidor mundial do produto.

2 Arroba: Medida de peso equivalente a 15 quilos. 


\section{O Café de Portinari}

Cândido Portinari (1903-1962), pintor brasileiro, nasceu na fazenda Santa Rosa, num vilarejo bem próximo da cidade de Brodósqui, no interior do Estado de São Paulo, cuja principal atividade era a plantação de café.

Desde criança, mostrou habilidades artísticas. Estudou apenas os primeiros quatro anos iniciais de ensino. Quando alcançou a idade de 15 anos viajou para São Paulo para ingressar ao Liceu de Artes e Ofícios de São Paulo e dar continuidade aos estudos de desenho e pintura, queria homenagear sua terra e o povo brasileiro, por meio da sua arte.

Os camponeses foram fontes de inspiração para Portinari compor suas obras, reconhecidas e respeitadas internacionalmente. Muitas das suas pinturas retrataram a vida no campo, as esperanças dos trabalhadores rurais brasileiros. "Cândido Portinari é uma expressão constante e fiel de nossa cultura, porque traduz, em sua arte, as dores e as esperanças de nosso povo" (FABRIS, 1990, p. 37). Observe a pintura a seguir:

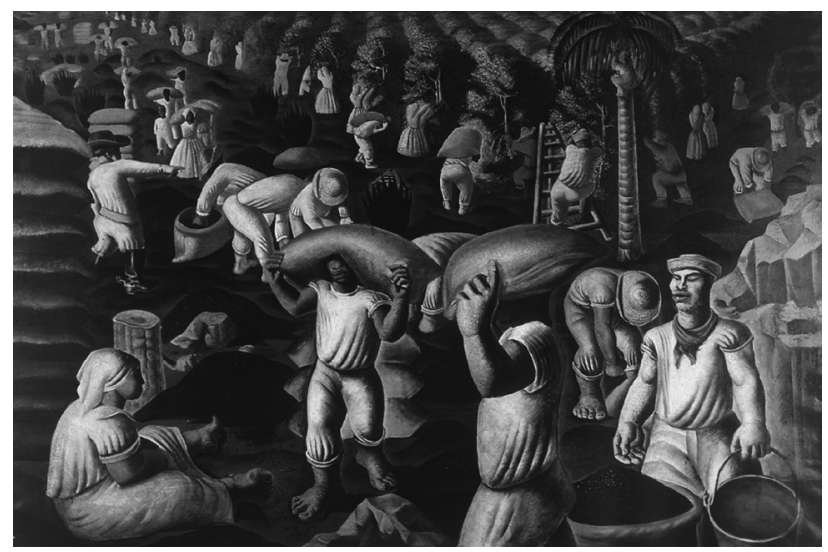

Café. Cândido Portinari, 1935. Pintura a óleo sobre tela de tecido. $1,30 \mathrm{~m}$ de altura por $1,95 \mathrm{~m}$ de largura.

O artista muitas vezes utilizou materiais simples por não possuir recursos e valer-se de um material de melhor qualidade. Esta obra foi reconhecida no exterior numa exposição internacional do Carnegie Institute de Pittsburgh, Estados Unidos, em Nova York, no ano de 1935.

O olhar rural de Portinari visualizava a força do trabalho braçal e manual dos escravos e camponeses que trabalhavam nas fazendas de café. Homens e 
mulheres foram representados. Observa-se que nos dois primeiros planos da pintura, os homens, devido à força e estrutura física, eram os principais carregadores das sacas de café colhidas, em sua maioria, pelas mulheres; somente as mulheres com boa resistência física carregavam as sacas.

No terceiro e último plano, temos a colheita, na qual a maioria dos colhedores são mulheres, a roupa usada as diferencia dos homens. Observe o detalhe da obra de Portinari:

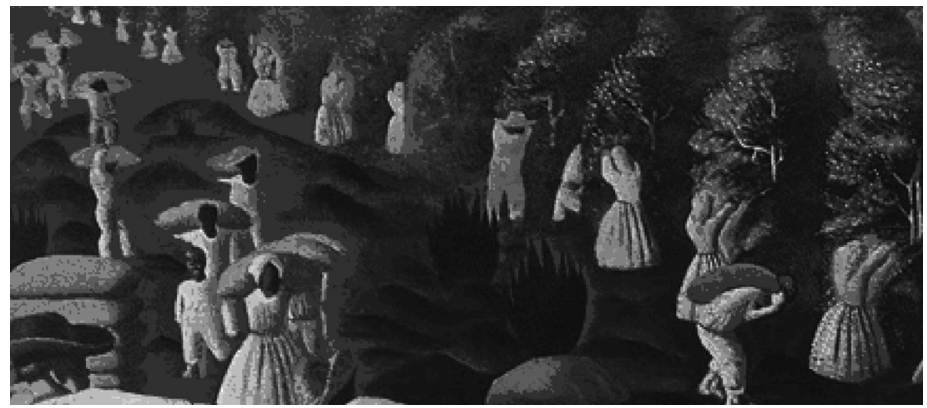

Há possibilidade de os poucos homens colhedores representados por Portinari serem idosos. Uma forma de comparação às mulheres, com sua fragilidade.

Homens e mulheres que formam a sociedade e as relações construídas ao longo da história mudando-as, continuamente, manifestam-se de formas diferentes, dependendo dos lugares onde se encontram e da época que vivenciam, são representados por Portinari nesta obra "Café". É a imagem de uma parte da sua história de vida infantil, que põe em evidência não só o trabalho na colheita do café nas fazendas, mas também, a harmonia do trabalho entre homens e mulheres com suas peculiares diferenças.

A obra mostra o retrato de uma cena de colheita de café, típica da região de origem do artista, Brodósqui. Nela, é colocada em evidência a importância da mulher e do homem como trabalhadores, colaboradores do desenvolvimento econômico brasileiro, já que são os responsáveis pela riqueza comercial do produto e do sucesso de venda no exterior, apresentando, assim, o Brasil ao mundo.

Portinari foi brilhante enquanto representador não só da riqueza café, mas também, da representação do homem e da mulher como parte dessa riqueza. Como seres de profunda força e envolvimento com o trabalho braçal, com a terra que lhes dá o sustento. Pés e braços dos trabalhadores foram representados numa forma enorme, isto é, desproporcional ao corpo, parecem ligar-se a terra, como dela fazendo parte. 
A mulher retratada pelo artista mostra sua força e fragilidade, ao mesmo tempo, participa lado a lado no trabalho de colheita do café com o homem. No entanto, Portinari representa, também, em primeiro plano, uma mulher sentada descansando, é a confirmação da fragilidade dessa mulher em trabalhos onde o esforço físico é o principal agente.

O poder masculino, também, é abordado pelo artista na obra, observe outro detalhe:

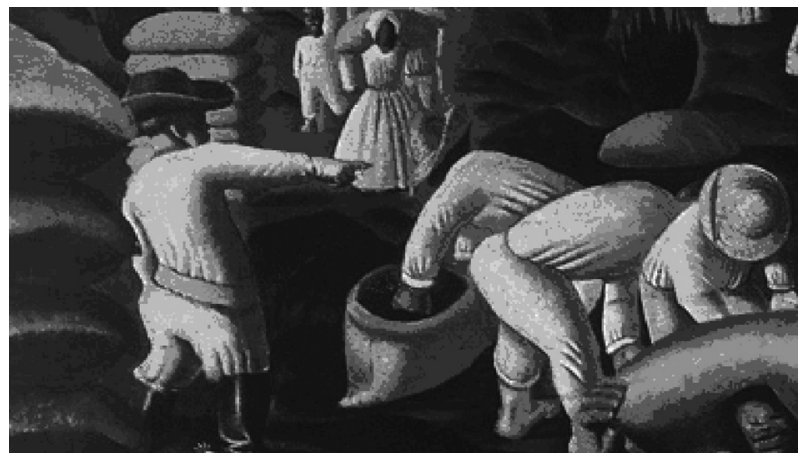

O trabalho dos colhedores de café é fiscalizado e ordenado por um possível capataz da fazenda, em pé, calçado, com seu braço direito esticado, cujo dedo indicador aponta, ordena, acusa com altivez e determinação, evidenciando o poder masculino.

Observe que o corpo desse homem não apresenta a deformação desproporcional dos colhedores de café. Isso, provavelmente, deve-se ao fato deste, não ser aquele que se envolve com o trabalho braçal, com o esforço do ato de carregar sacas de café e muito menos de realizar caminhadas na jornada do seu trabalho, num ir e vir da colheita, seu trabalho se diferencia dos outros na mesma medida em que sua representação corporal é diferenciada.

Portinari, além de plasticamente expressivo e social é técnico e esta técnica envolve a matemática.

\section{Relações matemáticas}

Como abordado anteriormente, a deformação dos personagens da obra "Café" é proposital, há uma desproporção corporal, contrapondo as regras de proporção matemática. 
A regra de proporção tem fundamento no pensamento grego, na qual a base da representação da beleza era quantitativa. Sua concepção era matemática, isto é, a beleza tinha proporção num conjunto de elementos muito próximos do ideal nas representações corporais, mas principalmente na harmonia dessas proporções. Quando uma parte do corpo parecia desproporcional ao todo, era caracterizado como feio.

A beleza era o que o conjunto poderia proporcionar de agradável aos olhos, o braço não poderia por si só ser belo, mas somente em todo o esquema do corpo humano.

Por volta de 1500, no Renascimento, Michelangelo e principalmente Da Vinci, colocaram a proporção em evidência em suas obras de arte.

Da Vinci, como cientista, valia-se de cadáveres para medir a proporção do corpo, descobrindo, assim, que nenhuma outra coisa obedece tanto a Divina Proporção, como o corpo humano. Leonardo Da Vinci ilustrou esta afirmação com o desenho do "Homem Vitruviano" (CARREIRA, 2000).

A Divina proporção, criação grega era, basicamente, um retângulo, do qual havia proporções, um lado maior dividindo o menor e, a partir dessa proporção, tudo era construído. A profundidade, por exemplo, era dividida pelo comprimento ou altura.

Em 1200, Leonardo Fibonacci, um matemático estudioso da criação de coelhos, descobriu o que, possivelmente, é a mais famosa das sequências matemáticas: a Série de Fibonacci.

Tomado dois coelhos, um macho e uma fêmea, Fibonacci contou como eles se reproduziam e chegou a uma sequência em que um número é igual a soma dos números anteriores, vejamos:

$$
\begin{aligned}
1 & \\
1+1 & =2 \\
2+1 & =3 \\
3+2 & =5 \\
5+3 & =8 \\
8+5 & =13 \\
13+8 & =21 \ldots
\end{aligned}
$$

Na famosa sequência de Fibonacci, série em que cada número é obtido pela soma dos dois anteriores: $1,1,2,3,5,8,13,21,34,55 \ldots$, aparece claramente a proporção áurea quando dividimos um número pelo seu

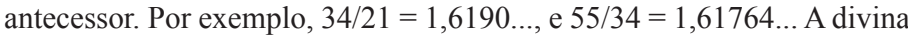
proporção também é encontrada no corpo humano. Se dividirmos a altura 
total de uma pessoa pela altura do seu umbigo até o chão, teremos a razão áurea (ATALAY, 2007).

Essa descoberta de Fibonacci trouxe abertura para os cientistas estudarem a natureza em termos matemáticos.

Os cientistas descobriram, por exemplo, que a proporção de abelhas fêmeas em comparação com abelhas machos numa colmeia é sempre de 1,618 e que a proporção que aumenta o tamanho das espirais de um caracol, também é de 1,618 .

Euclides de Alexandria (365 a.C. - 300 a.C.) [...] elaborou a teoria da proporção áurea, onde dois números (X e Y, por exemplo) estão em proporção áurea se a razão entre o menor deles sobre o maior for igual ao maior sobre a soma dos dois (ou seja, $\mathrm{X} / \mathrm{Y}=\mathrm{Y} / \mathrm{X}+\mathrm{Y}$ ). Esta proporção estabelece um coeficiente áureo, onde se pode analisar que, basicamente, tudo que se encontra na natureza está inscrito nesta proporção, seja o corpo humano, uma colméia de abelhas, uma estrela do mar, uma concha, etc. (FERRAZ, 2004).

Nós podemos perceber, embora visualmente, que existem proporções entre o corpo de um homem, de uma criança e um bebê. Porém, numericamente, elas podem ser verificadas.

Num homem, pode a cabeça estar para a altura do corpo 1 para 7 e as pernas 1 para, aproximadamente, 4 . Numa mulher, pode a cabeça estar para a altura do corpo na proporção 1 para 6 , para as pernas na proporção 1 para 3 , isto porque, de adulto para adulto, a proporção pode variar.

Nos desenhos artísticos, o mais importante é a expressão da ideia, não regras matemáticas a serem seguidas.

Portinari revelou-nos muito bem essa ideia como vimos na leitura da obra "Café", na qual as pessoas têm mãos, pés e braços desproporcionais, revelando a vida dura dos trabalhadores, o trabalho excessivo que levavam.

Porém, muitos artistas utilizam, intuitivamente, as relações matemáticas ao compor suas obras.

Além da proporção, podemos perceber na obra "Café" de Portinari a perspectiva. Observe o esboço feito pelo pintor antes de dar lugar à tinta. 


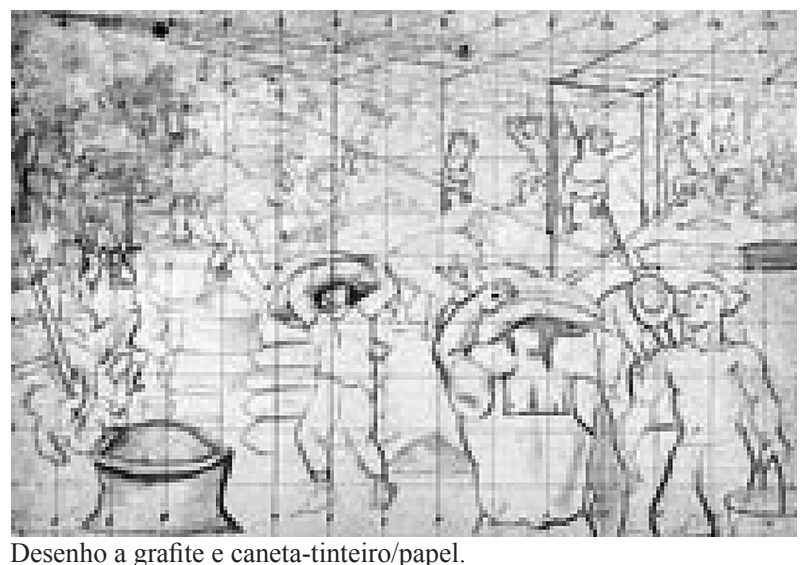

Este desenho é uma preparação para a obra "Café", apresenta $40 \mathrm{x}$ $58 \mathrm{~cm}$.

Percebemos linhas paralelas, linhas perpendiculares, ponto de fuga entre outros elementos matemáticos.

\section{Considerações finais}

Quando pensamos em leitura, normalmente nos referimos a textos escritos, porém obras de arte e matemática podem e devem ser lidas.

Aqui neste texto, pudemos realizar dois tipos de leitura, a escrita e a de imagem, pudemos relacioná-las com gênero e matemática. A imagem é um importante recurso de comunicação de ideias, além da facilidade de serem lembradas.

Arte, matemática e história se complementaram neste estudo, há uma variedade de assuntos que puderam ser abordados. Fatos puderam ser lembrados, revelando o entendimento de como a sociedade se organizou, como se concebem as formas e muitos outros "como" que envolvem nossa curiosidade e pensamento, aprendemos a ler o mundo quando há incentivo à percepção.

Na obra "Café" de Portinari, a percepção, o pensamento, as representações gráficas, estruturais, a lógica e a relação com a realidade são totalmente conscientes e propositais. "Segundo Arnheim (1989), a percepção e o pensamento precisam um do outro. A tarefa da percepção é reunir a matéria-prima 
necessária ao conhecimento e o pensamento processa essa percepção" (BARTH, 2006, p. 82).

Na leitura de uma imagem devemos:

Contemplar o que é visível, o perceptível, traduzido na intencionalidade (tema da obra, linhas utilizadas, formas geométricas ou orgânicas, claro/ escuro, etc.), a composição (predomínio do tipo de linhas, repetição de elementos, equilíbrio, etc.), as propriedades físicas (dimensões da obra, se é gravura, desenho, pintura, etc.), as propriedades expressivas (sensação, conflito, emoção, valores sociais, políticos, etc.) e a técnica utilizada (materiais empregados: pincéis, lápis, tinta, madeira, metal, pedra, etc.). E, completando [...] a interpretação pessoal (experiência, vivência, etc.). Há, então, aqui, a contribuição, os caminhos que a Arte enquanto conhecimento proporciona à análise de uma obra (BARTH, 2006, p. 85).

Procurou-se, neste texto, aliar a leitura tanto histórica quanto da linguagem do pensamento visual, artístico e matemático. Espera-se que a intenção de evidenciar que as imagens, a intuição, a reflexão, a análise do que se vê tenha sido exposta de forma clara e que tenha havido entendimento de que a organização do pensamento faz parte do processo de domínio do conhecimento cognitivo.

\section{REFERÊNCIAS}

ATALAY, B. A matemática e a Mona Lisa: A confluência da arte com a ciência. Tradução de: Mario Vilela. 2007. Disponível em: <http://www.sosni.com.br/html/modules.php? name $=$ Sections $\&$ op $=$ viewarticle $\&$ artid $=744>$. Acesso em: 02/03/2008.

BARTH, G. M. P. Arte e Matemática, subsídios para uma discussão interdisciplinar por meio das obras de M. C. Escher. Dissertação (Mestrado) - UFPR, Curitiba, 2006.

CALDAS, S. T.; D’ALESSIO, V. Café: um grão de história. São Paulo: Dialeto, 2006.

CARREIRA, E. J. A. N. (Org.). Os escritos de Leonardo Da Vinci sobre a Arte da Pintura. Brasília: Editora Universidade de Brasília; São Paulo: Imprensa Oficial do Estado de São Paulo, 2000. 
FABRIS, A. Portinari: pintor social. São Paulo: Perspectiva, 1990.

FERRAZ, H. Sistemas de Proporções Matemáticas. Revista Eletrônica de Ciências. Artigo n. 26, abr. 2004. Disponível em: <http://www.cdcc.sc.usp.br/ciencia/artigos/ art_26/proporcao.html $>$. Acesso em: 02/03/2008.

IMENES, L. M. P; JAKUBO; LELLIS. Proporções. São Paulo: Atual, 1992.

LIMA, D. R. Cafeina e saúde. Rio de Janeiro: Record, 1989.

MOREIRA, M. A vida dos grandes brasileiros: Cândido Portinari. Edição Exclusiva para Assinantes. São Paulo: Três, 2001.

MARTINS, A. L. Império do Café: A grande lavoura no Brasil 1850 a 1890. 7. ed. São Paulo: Atual, 1990.

NEVES, C. A estória do café. Rio de Janeiro, Instituto Brasileiro do Café, 1974.

PASCOAL, L. N. Cronologia histórica do café no mundo: the aroma of coffee. São Paulo: Editora Fundação Educar, 1999.

PROJETO PORTINARI. Acervo. Disponível em: <http://www.portinari.org.br>. Acesso em: 26/01/2008.

TAUNAY, A. de E. História do café no Brasil: no Brasil Imperial 1822-1872. Rio de Janeiro: Departamento Nacional do Café, 1939.

TOLEDO, V. V. de. Sua Majestade o café. São Paulo: Moderna, 1992.

Texto recebido em 11 de agosto de 2008 . Texto aprovado em 3 de dezembro de 2008. 